\title{
In search of ice-stream sticky spots
}

\author{
Richard B. AlLEY \\ Earth System Science Center and Department of Geosciences, The Pennsylvania State University, University Park, \\ Pennsylvania 16802, U.S.A.
}

\begin{abstract}
The basal shear stress of an ice stream may be supported disproportionately on localized regions or "sticky spots". The drag induced by large bedrock bumps sticking into the base of an ice stream is the most likely cause of sticky spots. Discontinuity of lubricating till can cause sticky spots, but they will collect lubricating water and therefore are unlikely to support a shear stress of more than a few tenths of a bar unless they contain abundant large bumps. Raised regions on the ice-air surface can also cause moderate increases in the shear stress supported on the bed beneath. Surveys of large-scale bed roughness would identify sticky spots caused by bedrock bumps, water-pressure measurements in regions of thin or zero till might reveal whether they were sticky spots, and strain grids across the margins of ice-surface highs would show whether the highs were causing sticky spots. Sticky spots probably are not dominant in controlling Ice Stream B near the Upstream B camp, West Antarctica.
\end{abstract}

\section{INTRODUCTION}

An ice stream with spatially variable basal drag might behave in fundamentally different ways from one with uniform drag. Recent data from the Siple Coast ice streams of West Antarctica (Table 1) are consistent with, although not proof of, the existence of localized sticky spots supporting high basal shear stress and surrounded by a generally well-lubricated, low shear-stress bed. Here, I use simple theory and available data to explore the possible behavior of variations in basal drag. My goals are to recommend field experiments to study such variations and to provide an interim assessment of their likely importance to ice-stream dynamics, pending the outcome of field work.

Modern ice-flow models typically resolve variations in basal drag on length scales $>O(10 h)$ and perhaps $>O(h)$, where $h$ is the ice thickness (e.g. Whillans and Johnsen, 1983; Balise and Raymond, 1985), but rely on parameterizations for sub-grid-scale basal processes. However, the parameteriz-ations (e.g. Weertman, 1964) typically are based on physics of processes at length scales $<O(10 \mathrm{~m})$, which are assumed to apply homogeneously to the intermediate length scale of $O(10 \mathrm{~m})$ to $O(h$ to $10 \mathrm{~h})$. Inhomogeneity of basal drag at this intermediate scale would produce sub-grid-scale sticky spots, which are my concern here.

Lliboutry (1987) stressed the possibility that freezing of inland ice to high spots of bedrock roughness from the decametric $\left(10^{1} \mathrm{~m}\right)$ to the kilometric $\left(10^{3} \mathrm{~m}\right)$ scale may produce sticky spots in regions of widespread basal melting. This may contribute significantly to restraint of ice flow in central regions of East Antarctica and West Antarctica, where ice velocities are low despite apparently high basal water pressure. Lliboutry noted that freezing of fast-moving ice to basal highs is unlikely, because the rapid motion would dissipate enough heat to melt the ice. I concentrate on fast-moving ice streams, and therefore do not consider thermal sticky spots further here.

Table 1. Evidence suggesting spatially variable drag under Siple Coast ice streams

Evidence $\quad \begin{gathered}\text { Location } \\ \text { (Ice Stream) }\end{gathered}$

\begin{tabular}{|c|c|c|}
\hline $\begin{array}{l}\text { Localization of } \\
\text { crevassing }\end{array}$ & B & $\begin{array}{l}\text { Vornberger and Whillans, } \\
1986\end{array}$ \\
\hline $\begin{array}{l}\text { Apparent-flow } \\
\text { inhomogeneities }\end{array}$ & B & Whillans and others, 1987 \\
\hline $\begin{array}{l}\text { Spatially variable } \\
\text { basal conditions }\end{array}$ & B & $\begin{array}{l}\text { Rooney and others, 1987; } \\
\text { Rooney, 1988; Atre and } \\
\text { Bentley, 1990 }\end{array}$ \\
\hline \multirow[t]{2}{*}{$\begin{array}{l}\text { Rare brittle fracture } \\
\text { near base }\end{array}$} & B & $\begin{array}{l}\text { Blankenship and others, } \\
\text { 1987a }\end{array}$ \\
\hline & C & $\begin{array}{l}\text { Anandakrishnan } \\
\text { and Bentley, } 1993\end{array}$ \\
\hline \multirow{2}{*}{$\begin{array}{l}\text { Inversions for basal } \\
\text { drag }\end{array}$} & $\mathrm{E}$ & MacAyeal, 1992 \\
\hline & B & $\begin{array}{l}\text { Whillans and Van der } \\
\text { Veen, } 1993\end{array}$ \\
\hline $\begin{array}{l}\text { Model calculations } \\
\text { from borehole data }\end{array}$ & B & Kamb, 1991 \\
\hline
\end{tabular}



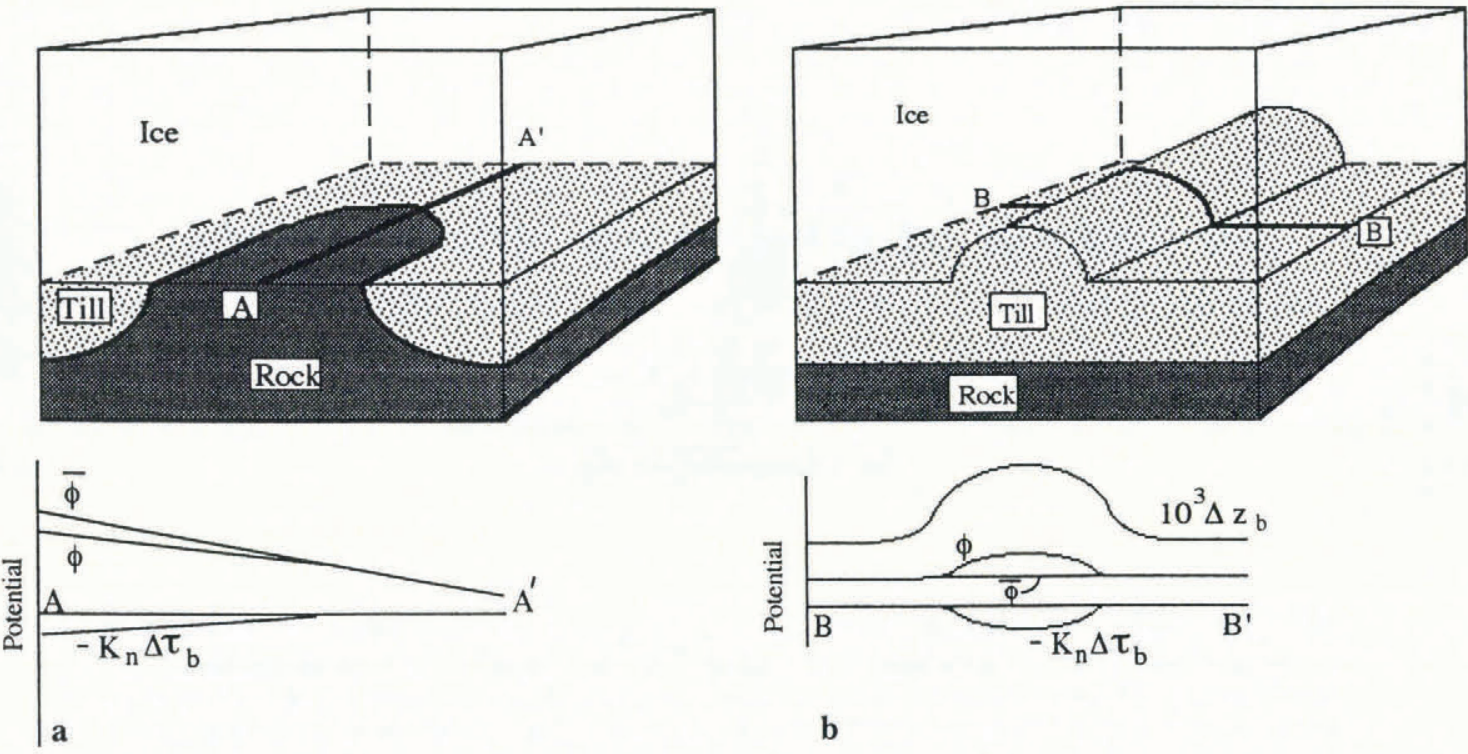

b
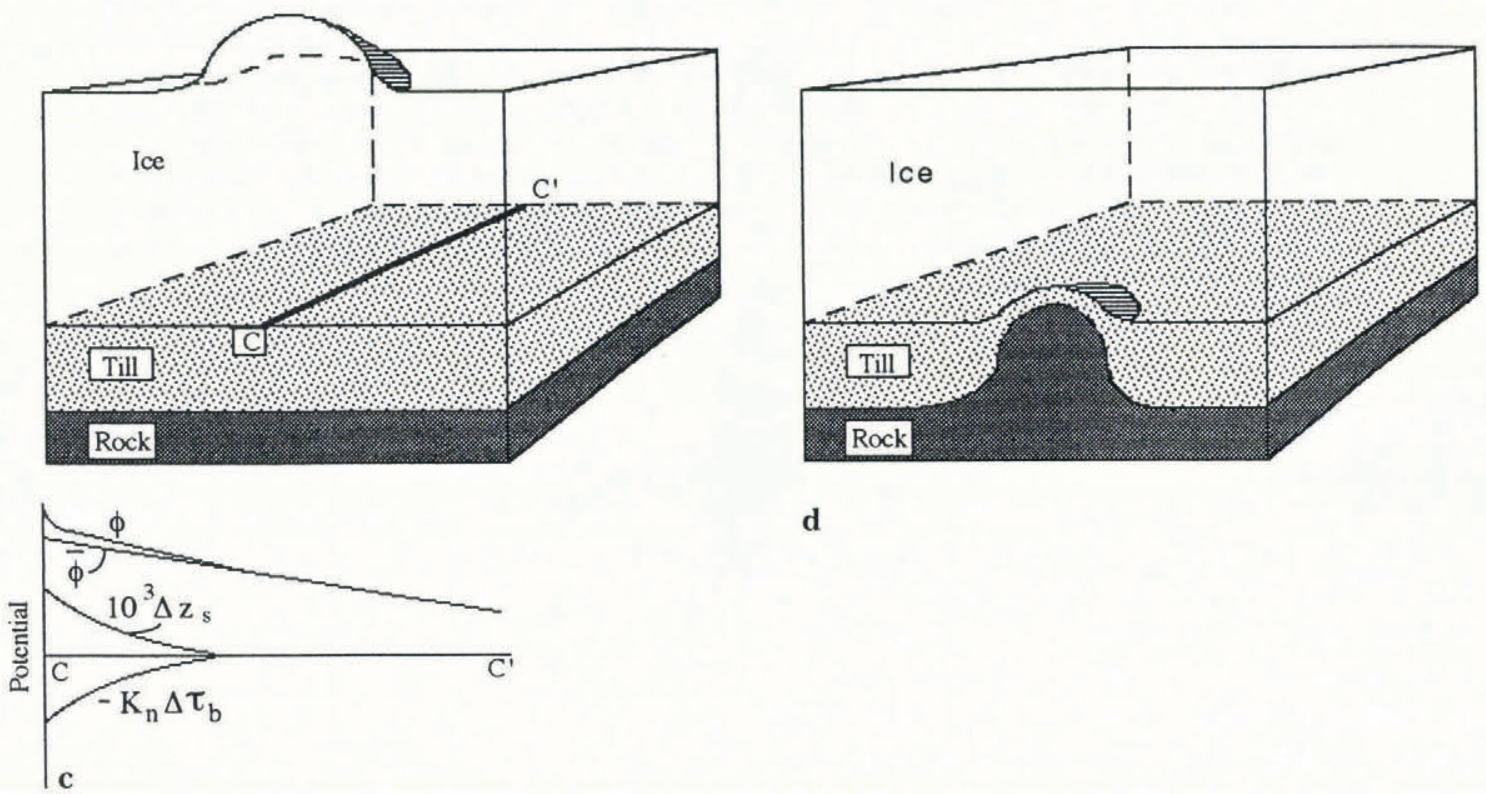

d

Fig. 1. Cartoons of sticky spots and their effects on steady subglacial hydraulic potentials. The potential is $\Phi=$ $\bar{\Phi}+10^{4} \Delta z_{\mathrm{s}}+10^{3} \Delta z_{\mathrm{b}}-K_{\mathrm{n}} \Delta \tau_{\mathrm{b}}$, where $\bar{\Phi}$ reflects the large-scale average relative to an arbitrary datum, and $\Delta z_{\mathrm{s}}$, $\Delta z_{\mathrm{b}}$ and $\Delta \tau_{\mathrm{b}}$ are perturbations in the surface and bed elevation and shear stress, respectively, from regional trends. a. Sticky spot caused by discontinuity of soft till, without perturbation of upper or lower surfaces of ice. If the shear stress rises too rapidly away from the rock outcrop, water will flow towards the outcrop from all sides and accumulate there. This will lubricate the sticky spot and limit its shear stress. $b$. Sticky spot caused by a long flute of the same material as the rest of the bed, without perturbation of upper ice surface. Water will drain away from the flute, reducing the lubrication and increasing the shear stress on the flute above that for a horizontal bed. From Equation (6), this geometric effect of the flute is $\Delta \tau_{\mathrm{b}} \leq 10^{3} \Delta z_{\mathrm{b}} / K_{\mathrm{n}}$, where the one-dimensional solution now is transverse to the long flute and the regional potential gradient in that direction is zero. $c$. Surface high over an unperturbed bed. The geometric perturbation raises the hydraulic potential locally and allows an increased shear stress, which in turn lowers the hydraulic potential to reach a balance. From Equation (6), the increase in shear stress under the surface high is $\Delta \tau_{\mathrm{b}} \leq 10^{4} \Delta z_{\mathrm{s}} / K_{\mathrm{n}}$.d. Sticky spot caused by a bedrock $k n o b$, with or without a lubricating layer of till on top. Ice flows around such a feature by enhanced creep, with little effect from lubrication tangential to the surface. A water-filled cavity may form in the lee of such a feature but may be largely isolated from the general subglacial water flow; hence, no cartoon of potential is shown.

\section{SIMPLE MODELS}

In the following sections, I define four sticky-spot models, discuss their geometry (Fig. la-d) and evaluate the likelihood of their existence under an ice stream. I pay special attention to how "sticky" each might be; i.e. to the maximum shear stress that could be supported on each.

\subsection{Interconnected water}

Suppose that a bed of an ice stream is thawed everywhere, such that a soft deformable till prevents high basal shear stress in most areas, but that discontinuity of the till allows sticky spots (Fig. 1a). High basal water pressure is needed to make till soft. Sticky spots then will have high 
basal water pressure; otherwise, water would flow into them from the surrounding till and accumulate until their water pressure was raised. Mountain glaciers move with ice-stream velocities if basal water pressures are high and shear stresses approach $100 \mathrm{kPa}$ (e.g. Kamb and others, 1985; Iken and Bindschadler, 1986). Thus, if their velocity-dependence on water pressure and shear stress is similar to those of mountain glaciers, ice-stream sticky spots of the type shown in Figure la should not support basal shear stresses much over $100 \mathrm{kPa}$.

A postulate by Weertman (1972), if true, places a more restrictive upper limit on the shear stress supported by sticky spots of this type. Weertman (1972) suggested that the potential function that drives subglacial water flow is

$$
\Phi=\rho_{\mathrm{i}} g\left(z_{\mathrm{s}}-z_{\mathrm{b}}\right)+\rho_{\mathrm{w}} g z_{\mathrm{b}}-K_{\mathrm{n}} \tau_{\mathrm{b}}
$$

where $g$ is the gravitational acceleration, $\rho_{\mathrm{i}}$ is the density of ice, $\rho_{\mathrm{w}}$ is the density of water, $z_{\mathrm{s}}$ is the ice-surface elevation, $z_{\mathrm{b}}$ is the elevation of the glacier bed, $\tau_{\mathrm{b}}$ is the basal shear stress and $K_{\mathrm{n}}$ is a non-dimensional constant of $O(1)$. The first two terms on the righthand side of Equation (1) account for the ice-overburden pressure and the potential due to the elevation of the subglacial water.

Weertman (1972; also Robin and Weertman, 1973) based the third term on the righthand side of Equation (1) on the following assumptions:

(a) The basal shear stress is supported by the form drag of bumps on the glacier bed rather than by any adhesion of ice to the bed.

(b) Ice flow over these bumps creates high-pressure and low-pressure regions.

(c) Basal water is squeezed out of the high-pressure regions and accumulates in the low-pressure regions.

(d) The low-pressure regions are interconnected and allow water drainage.

(e) The variability of ice-bed contact pressure increases with increasing shear stress, causing the water pressure to decrease with increasing shear stress.

Points (a)-(d) are supported by observations that the water pressure beneath Upstream B camp ( $\mathrm{UpB}$ ) on Ice Stream B, West Antarctica, is slightly less than the iceoverburden pressure (Blankenship and others, 1987b; Engelhardt and others, 1990). Point (e) has not been tested, so Equation (1) must be considered an hypothesis.

In support of Equation (1), however, a decrease in water potential with increasing shear stress is a common feature of many steady-state basal models, including both cavity and film types (e.g. Walder, 1986; Kamb, 1987; Lliboutry, 1987; Alley, 1989a). The close approach of subglacial water pressure $\left(P_{\mathrm{w}}\right)$ to ice-overburden pressure $\left(P_{\mathrm{i}}\right)$ beneath inland ice at Byrd Station ( $P_{\mathrm{i}}-$ $P_{\mathrm{w}} \approx 140 \mathrm{kPa}$; Alley and others, 1987a) and beneath $\mathrm{UpB}\left(P_{\mathrm{i}}-P_{\mathrm{w}} \approx 50 \mathrm{kPa}\right.$; Blankenship and others, 1987b), with both water potentials far above the boundary condition of flotation at the grounding line (by about $14 \mathrm{MPa}$ for Byrd Station and $2.5 \mathrm{MPa}$ for $\mathrm{UpB}$ ), suggests that a "local" equation such as Equation (1) with no dependence on the grounding-line potential is appropriate in West Antarctica. Also, West Antarctica lacks the large non-steady forcings through moulins and low- pressure channels that might complicate application of Equation (1) to a temperate mountain glacier. Thus, I will adopt Equation (1) for further calculations.

The third term on the righthand side of Equation (1) is properly ignored in models at the ice-sheet scale, although it must be considered for sticky spots. To see its insignificance at the ice-sheet scale, compare it to the first two terms in Equation (1):

$$
\gamma \equiv \frac{K_{\mathrm{n}} \tau_{\mathrm{b}}}{\rho_{\mathrm{i}} g\left(z_{\mathrm{s}}-z_{\mathrm{b}}\right)+\rho_{\mathrm{w}} g z_{\mathrm{b}}} .
$$

For simplicity, set $z_{\mathrm{b}}=0$, with $z_{\mathrm{s}}-z_{\mathrm{b}}=h$. At the icestream or ice-sheet scale, $\tau_{\mathrm{b}} \sim \rho_{\mathrm{i}} g h(h / L)$, where $L$ is the characteristic flow-line length and $h / L$ is the surface slope. Then $\gamma=K_{\mathrm{n}} h / L$. With $K_{\mathrm{n}} \sim 1$ and $h / L \sim 10^{-3}$, $\gamma \sim 10^{-3}$, which is insignificant.

The third term in Equation (1) is important at the sticky-spot scale, because of its effect on water flow and bed lubrication. Water flows in the negative direction of the potential gradient $\Psi \equiv \nabla \Phi$. Simplifying Equation (1) to one dimension for convenience and calculating $\Psi_{1-\mathrm{d}}$ with $K_{\mathrm{n}}$ assumed independent of position yields

$$
\begin{gathered}
\Psi_{1-\mathrm{d}}=\rho_{\mathrm{i}} g \frac{\partial z_{\mathrm{s}}}{\partial x}+\left(\rho_{\mathrm{w}}-\rho_{\mathrm{i}}\right) g \frac{\partial z_{\mathrm{b}}}{\partial x}-K_{\mathrm{n}} \frac{\partial \tau_{\mathrm{b}}}{\partial x} \\
\Psi_{1-\mathrm{d}} \approx 10^{4} \frac{\partial z_{\mathrm{s}}}{\partial x}+10^{3} \frac{\partial z_{\mathrm{b}}}{\partial x}-K_{\mathrm{n}} \frac{\partial \tau_{\mathrm{b}}}{\partial x}
\end{gathered}
$$

where dimensions are in the MKS system. Steady-state water drainage requires $\Psi_{1-\mathrm{d}}<0$, which places constraints on $\left(\partial \tau_{\mathrm{b}}\right) /(\partial x)$ and thus on how sticky a sticky spot of given size can be.

We can write $\Psi_{1-\mathrm{d}}$ as

$$
\Psi_{1-\mathrm{d}}=\bar{\Psi}_{1-\mathrm{d}}+10^{4} \frac{\partial z_{\mathrm{s}}^{\prime}}{\partial x}+10^{3} \frac{\partial z_{\mathrm{b}}^{\prime}}{\partial x}-K_{\mathrm{n}} \frac{\partial \tau_{\mathrm{b}}^{\prime}}{\partial x}
$$

where primes indicate perturbations from the regional trends and $\bar{\Psi}_{1-\mathrm{d}}$ is the regional potential gradient averaged over distances that are long compared to the 10 ice-thickness upper limit on sticky-spot size. As shown in Equation (2), $\bar{\Psi}_{1-\mathrm{d}}$ depends on the regional surface and bed slopes but not on gradients in basal shear stress. If we approximate a sticky spot as having maximum perturbations of $z_{\mathrm{s} \max }^{\prime} \equiv \Delta z_{\mathrm{s}}$ and $z_{\mathrm{b} \max }^{\prime} \equiv \Delta z_{\mathrm{b}}$ over length $x_{\mathrm{s}}$, and require $\Psi_{1-\mathrm{d}}<0$ to allow steady-state drainage, then the perturbation of the shear stress, $\Delta \tau_{\mathrm{b}}$, must be

$$
\Delta \tau_{\mathrm{b}}<\frac{\left(-\bar{\Psi}_{\left.1-\mathrm{d} x_{\mathrm{s}}+10^{4} \Delta z_{\mathrm{s}}+10^{3} \Delta z_{\mathrm{b}}\right)} .\right.}{K_{\mathrm{n}}} .
$$

If the sticky spot is $x_{\mathrm{s}}<10 h$ in length, then $\Delta \tau_{\mathrm{b}}$ has a maximum value, $\Delta \tau_{\mathrm{b} \max }$, given by

$$
\Delta \tau_{\mathrm{b} \max }=\frac{-10 h \bar{\Psi}_{1-\mathrm{d}}+10^{4} \Delta z_{\mathrm{s}}+10^{3} \Delta z_{\mathrm{b}}}{K_{\mathrm{n}}} .
$$

Equation (6) shows that if the ice-surface and bed slopes are not perturbed from their regional averages, the shear stress on a sticky spot can exceed that in surrounding, well-lubricated regions by no more than $-10 h \bar{\Psi}_{1-\mathrm{d}} / K_{\mathrm{n}}$. This can be increased if the bed is raised (e.g. over a drumlin or flute; Fig. 1b) or the surface is raised (e.g. beneath an ice raft; Fig. 1c), with perturbations in surface elevation potentially ten times more effective than perturbations in bed elevation. 


\subsection{Isolated bumps}

Equation (1) is based on Weertman's (1972) interpretation of the basal-sliding models of Nye (1969) and Kamb (1970). Those models assumed Fourier beds with small slopes and continuous roughness spectra (usually calculated for white roughness), and Weertman (1972) assumed an interconnected water system responding to that roughness. These assumptions need not be valid - a drumlin field may have little roughness between the clast size and the drumlin size, for example. It is common in models to separate the drag of the larger bumps $(>O)$ $1 \mathrm{~m})$ ) and their interaction with the basal-water system from the effects of smaller obstacles (e.g. Weertman, 1986).

Ice moves over large bumps primarily by enhanced creep. For a white-roughness bed, most of the restraint on ice flow is provided by relatively small bumps $\left(O\left(10^{-3}\right.\right.$ $10^{-2} \mathrm{~m}$ amplitude)), and restraint decreases with increasing bump size. However, a deforming till may allow the smaller obstacles to move with the ice, causing large obstacles fixed in the bedrock to provide the major restraint to ice flow (Fig. 1d).

The force, $D$, needed to move ice at velocity $u$ over a large, equant obstacle of typical dimension $a$ is approximately

$$
D \sim\left(\frac{a^{5} u}{A}\right)^{1 / n}
$$

where $u$ is the pre-factor and $n=3$ is the exponent for power-law creep (e.g. Weertman, 1964). This result is controlled primarily by the form drag of the bump (the geometric requirement that ice moves around the obstacle) rather than dynamic drag (the tangential friction between the ice and the obstacle (Weertman, 1964)). The drag for a free-slip boundary between ice and bump is two-thirds of that for a no-slip boundary in linear-viscous ice ( $n=1$; Hallet, 1979; Watts, 1974), and $\left(\frac{2}{3}\right)^{\frac{1}{3}}=0.87$ of that for a no-slip boundary with $n=3$. Details of behavior at the boundary between ice and a large bump thus can be ignored to good approximation.

Sliding models usually assume that the number of obstacles per unit area of the bed, $N \sim a^{-2}$. For large obstacles $(a>O(0.1-1 \mathrm{~m}))$, the contribution of obstacles of size $a$ to the basal shear stress, $\tau_{\mathrm{a}}=N D$, then varies as

$$
\tau_{\mathrm{a}} \sim\left(\frac{u}{A a}\right)^{\frac{1}{3}} .
$$

Equation (8) contains the usual result that the importance of large obstacles in restraining basal sliding decreases with increasing size. However, as noted above, smaller obstacles in a deforming till may move past larger obstacles fixed in bedrock, so that $u=u(a)$. If $u$ increases more rapidly than $a$, then large obstacles will be more important in restraining ice flow than small ones and may act as sticky spots, regardless of whether the deforming layer passes over or around the larger obstacles.

\section{IN SEARCH OF SIPLE COAST STICKY SPOTS}

The new observations suggesting sticky-spot existence (Table 1) have been made on the Siple Coast ice streams of West Antarctica, and ongoing field programs offer the possibility of identifying and characterizing sticky spots there. The most comprehensive data set has been collected on Ice Stream B, especially near the UpB camp. In the next sections, I apply the general relations derived above to conditions on Ice Stream B to learn what sticky spots are likely there and how they might be detected.

\subsection{General considerations}

Characteristics of branch B2 of Ice Stream B between the 520 and $320 \mathrm{~m}$ surface-elevation contours are listed in Table 2 (Shabtaie and Bentley, 1988). The long-profile of the ice stream is concave-up and the ice thins downglacier, so the driving stress and the magnitude of the potential gradient for water flow could be increased or decreased, respectively, by moving the interval under consideration up-glacier or down-glacier.

The basal shear stress is not known. We (Alley and others, 19087b) estimated a local value of $\tau_{\mathrm{b}} \approx 20 \mathrm{kPa}$ near the Upstream B camp, based on assumed small sideshear stress and a measured (Shabtaie and Bentley, 1987) local driving stress of about $25 \mathrm{kPa}$, which is somewhat larger than the regional average of about $14 \mathrm{kPa}$ (Table 2). In contrast, Whillans and Van der Veen (1993) calculated very low - locally negative - basal shear stresses in parts of Ice Stream B just up-glacier from that section we studied, where the driving stress is locally much smaller than the regional average.

Table 2. Ice-stream characteristics. Data estimated from maps of Shabtaie and Bentley (1988) for branch B2 of Ice Stream $B$, between the 520 and $320 \mathrm{~m}$ surface-elevation contours

\begin{tabular}{|c|c|c|}
\hline$D z_{\mathrm{g}}$ & $200 \mathrm{~m}$ & $\begin{array}{l}\text { Change in sfc. elevation } \\
\text { along ice stream }\end{array}$ \\
\hline$D z_{\mathrm{b}}$ & $\approx 0^{*}$ & $\begin{array}{l}\text { Change in bed elevation } \\
\text { along ice stream }\end{array}$ \\
\hline$D x$ & $120-185 \mathrm{~km}$ & $\begin{array}{l}\text { Distance between irregular } \\
\text { contours }\end{array}$ \\
\hline$D z_{\mathrm{s}} / D x$ & $0.0014 \pm 0.003$ & Average sfc. slope \\
\hline$D z_{\mathrm{b}} / D x$ & $\approx 0^{*}$ & Average bed slope \\
\hline & $1100 \mathrm{~m}$ & Average ice thickness \\
\hline $\bar{\tau}_{\mathrm{d}}$ & $14 \pm 3 \mathrm{kPa}$ & $\begin{array}{l}\text { Average driving stress } \\
\quad \equiv \rho_{\mathrm{i}} g \bar{h} D z_{\mathrm{s}} / D x\end{array}$ \\
\hline $\bar{\Psi}$ & $-12 \pm 3 \mathrm{~Pa} \mathrm{~m}^{-1}$ & $\begin{array}{l}\text { Average hydrological } \\
\text { potential gradient along } \\
\text { ice flow } \equiv \rho_{\mathrm{i}} g D z_{\mathrm{s}} / D x \\
+\left(\rho_{\mathrm{w}}-\rho_{\mathrm{i}}\right) g D z_{\mathrm{b}} / D x\end{array}$ \\
\hline & $33 \mathrm{~km}$ & Average ice-stream width \\
\hline
\end{tabular}

Variable Value Meaning

* The bed is somewhat irregular but the results of calculations are not very sensitive to bed slopes, so typical values are assumed. 
Over long distances, gradients in longitudinal and bridging stresses should have little effect on the ice flow (Paterson, 1981, p. 101), leaving the sides and bed of the ice stream to support the driving stress. A side-shear stress of $100 \mathrm{kPa}$ would support about half of the average driving force from a typical ice-stream width of $33 \mathrm{~km}$ across branch B2, leaving a basal shear stress of $7 \pm 3 \mathrm{kPa}$. A side shear approaching $200 \mathrm{kPa}$ would support essentially the entire driving stress. Fabric development and strain heating in the shear margins might cause them to support less than $100 \mathrm{kPa}$ (Hughes, 1977), leaving a relatively large basal shear stress in excess of $10 \mathrm{kPa}$. I suggest an average basal shear stress of $10 \mathrm{kPa}$. The basal shear stress almost certainly lies between the driving stress and the unconfined strength of subglacial till in a shear box, which is around $2 \mathrm{kPa}$ (Kamb, 1991).

\subsection{Water-pressure measurements and discontin- uous till}

If soft till limits the basal shear stress on an ice stream, then localized regions of thin or no till such as imaged by Rooney and others (1987) should act as sticky spots, even though the upper and lower surfaces of the ice are not perturbed. Then provided Equation (1) proves to be valid, the water pressure over these thin-till regions should be lower than in surrounding regions. Thus, water-pressure measurements might be used to identify sticky spots.

The constant $K_{\mathrm{n}}$ in Equation (1) might be as small as $K_{\mathrm{n}} \approx 2$ for a rough bed, or as large as $K_{\mathrm{n}} \approx 9$ for a smooth bed (Kamb, 1970). A till bed is likely to be rough, based on theory and observation (see section on sliding in Alley (1989b)), so I choose $K_{\mathrm{n}}=3$ here with a likely range of $2 \leq K_{\mathrm{n}} \leq 5$.

For $h=1100 \mathrm{~m}, K_{\mathrm{n}}=3$ and $\bar{\Psi}=-12 \mathrm{~Pa} \mathrm{~m}^{-1}$, Equation (6) yields

$$
\Delta \tau_{\mathrm{b} \max }=44+3 \Delta z_{\mathrm{s}}+0.3 \Delta z_{\mathrm{b}} \mathrm{kPa}
$$

where $\Delta z_{\mathrm{s}}$ and $\Delta z_{\mathrm{b}}$ are perturbations in meters of surface and bed elevation, respectively, from the regional trends.

If sticky spots occupy fractional area $s$ and support shear stress $\tau_{\mathrm{b} s}$, and lubricated regions occupy fractional area $1-s$ and support $\tau_{b l}$, then force balance requires

$$
\bar{\tau}_{\mathrm{b}}=\tau_{\mathrm{b} s} s+\tau_{\mathrm{bl}}(1-s)
$$

where $\bar{\tau}_{\mathrm{b}}$ is the average basal shear stress. In the limit $s \rightarrow 0$ (few sticky spots), $\overline{\mathrm{t}}_{\mathrm{b}}=\tau_{\mathrm{b} l} \approx 10 \mathrm{kPa}$, and a sticky spot with $\Delta z_{\mathrm{g}}=\Delta z_{\mathrm{b}}=0$ (no topographic expression) might support a shear stress $\tau_{\mathrm{bs}}=\tau_{\mathrm{b} l}+\Delta \tau_{\mathrm{b} \max } \approx$ $10+44=54 \mathrm{kPa}$. The length scale used in Equation (6) may be too large by a factor of 2 (the shear stress must rise and then fall in the $10 \mathrm{~h}$ length allotted to the sticky spot), so $\tau_{\mathrm{bs}}$ might instead be $10+22 \approx 32 \mathrm{kPa}$.

The error range introduced here is important. Errors in estimating subglacial water pressures seismically or in boreholes are likely to be a few tens of $\mathrm{kPa}$ or more, even under favorable conditions (Alley and others, 1987a; Blankenship and others, 1987b; Engelhardt and others, $1990)$. With $K_{\mathrm{n}}=3, \Delta \tau_{\mathrm{b} \max }=44 \mathrm{kPa}$ might produce a detectable change in basal-water pressure, whereas the water-pressure effect of $\Delta \tau_{\mathrm{b} \max }=22 \mathrm{kPa}$ would be close to, or less than, the measurement error. Thus, we cannot tell whether a sticky spot without topographic expression would be detectable by its effect on water pressures measured with modern techniques, but such an experiment would not have a high probability of success.

A raised bed could increase the maximum possible water-pressure effect of a sticky spot, but this effect probably will not be important on Ice Stream B. From Equation (9), a feature $100 \mathrm{~m}$ high would be required to increase the maximum shear stress by $30 \mathrm{kPa}$, only marginally detectable in water-pressure measurements; however, seismic surveys near UpB by Rooney and others (1987) revealed no local roughness elements as large as $10 \mathrm{~m}$.

The data from near $\mathrm{UpB}$ allow rather restrictive limits to be estimated for the importance of sticky spots there. Rooney and others (1987) and Rooney (1988) conducted seismic studies just up-glacier of $\mathrm{UpB}$ in a region about $10 h$ by $10 h$, where $h \approx 1000 \mathrm{~m}$. They found that lowvelocity, presumably soft till covers $>97-98 \%$ of the bed, with till thinner than the seismic resolution of $2 \mathrm{~m}$ on $2-$ $3 \%$ of the bed. The ice surface and the bed were nearly smooth, so $\Delta z_{\mathrm{s}} \approx 0$ and $\Delta z_{\mathrm{b}} \approx 0$ in Equation (9) and $\Delta \tau_{\mathrm{b} \max }=44 \mathrm{kPa}$. Then, in Equation (10), $\tau_{\mathrm{b} s}<\tau_{\mathrm{b} l}$ $+44 \mathrm{kPa}$ and $s<0.03$. Estimating $\bar{\tau}_{\mathrm{b}}=10 \mathrm{kPa}$ from Table 2 (possibly the largest source of error, but a reasonable guess given the relatively high driving stress in the survey region), the lubricated regions support a shear stress of $\tau_{\mathrm{b} l}>8.7 \mathrm{kPa}$. Thus, the lubricated regions support more than $87 \%$ of the basal shear force, leaving $<13 \%$ of the basal-shear force supported on sticky spots and suggesting that sticky spots do not dominate the force balance in this region of Ice Stream B.

\subsection{Strain grids and ice raft " $\mathrm{a}$ "}

Surface topography is about ten times more effective than bed topography in affecting subglacial water flow and the "stickiness" of the bed. Suppose a local high with lateral dimensions similar to or larger than the ice thickness were placed on the ice surface over a homogeneous, unperturbed bed. This would raise the potential of underlying water, and would cause water from up-glacier to flow around the high. But, without a supply of lubricating water, the bed beneath the high should become stickier and support a higher shear stress. That, in turn, would lower the water potential beneath it, reducing the diversion of water. From Equation (9), the shear stress could not be increased by more than about $3 \Delta z_{\mathrm{s}} \mathrm{kPa}$, if $\Delta z_{\mathrm{B}}$ is in meters. A $10 \mathrm{~m}$ surface perturbation could produce a shear stress as much as $30 \mathrm{kPa}$ above the regional value.

Ice raft "a" (formerly ice rise "a"), near the mouth of Ice Stream B, is an elliptical feature about $10 \mathrm{~km}$ by $5 \mathrm{~km}$ with its long axis parallel to the ice flow, and stands a few meters above the surrounding ice (Bindschadler and others, 1987; Shabtaie and Bentley, 1987). Flow lines appear to pass around it, and its radar signature is different from its surroundings but similar to the signature of an ice rise in an ice shelf. It therefore appears to be a discrete mass of ice with ice-stream flow passing by, and is an obvious candidate for a sticky spot caused by surface topography. However, measurements indicate that its 
speed is similar to that of the surrounding ice or only slightly slower, by perhaps $10-20 \mathrm{~m} \mathrm{a}^{-1}$.

Assuming a height of $\Delta z_{8}=5 \mathrm{~m}$, Equation (9) predicts that the peak shear stress beneath the ice raft should exceed the regional value by no more than $15 \mathrm{kPa}$. Approximating the ice raft as a circular cylinder of radius $a=5 \mathrm{~km}$, and assuming linear variation of basal shear stress from the regional value at the margin to the maximum value at the center, the bed could support an excess shear force as large as $D \approx 10^{11} \mathrm{~N}$.

For linear fluid of viscosity $\mu$ flowing at right-angles to the axis of an infinite circular cylinder, the drag per unit length, $D / l$, is approximated by

$$
\begin{aligned}
D / l & =\frac{2 \pi \mu u}{\ln (7.4 / R)} \\
R & \equiv \frac{2 a u \rho}{\mu}
\end{aligned}
$$

where $\mu$ is the velocity of the fluid far from the cylinder relative to the cylinder, $\rho$ is the fluid density and $a$ is the cylinder radius (Batchelor, 1967, p. 243-44). For ice raft "a", $\rho=\rho_{\mathrm{i}} \approx 900 \mathrm{~kg} \mathrm{~m}^{-3}, a \approx 5000 \mathrm{~m}$, the total length, $l$, is the ice thickness of about $750 \mathrm{~m}$ and the drag force $D \leq 10^{11} \mathrm{~N}$. It is therefore possible to estimate an upper limit on the relative velocity of the ice past the ice raft if the viscosity can be estimated.

A force of $<10^{11} \mathrm{~N}$ distributed evenly over the surface of a cylinder $750 \mathrm{~m}$ high with a $5 \mathrm{~km}$ radius yields an average stress of $<4 \times 10^{3} \mathrm{~Pa}$. Using the longitudinal stresses calculated by Bindschadler and others (1987) from a strain grid near ice raft "a", the regional effective stress $\tau^{2} \approx\left(4 \times 10^{4} \mathrm{~Pa}\right)^{2}$. Including the local stress around the ice raft would not increase this greatly, so I assume that the regional effective stress applies near the ice raft. The effective viscosity can then be calculated as $\mu \approx 1 /\left(A \tau^{2}\right)$. Taking $A \approx 3 \times 10^{-25} \mathrm{~Pa}^{-3} \mathrm{~s}^{-1}$, appropriate for a temperature of $-15^{\circ} \mathrm{C}$ (Paterson, 1981, p. 39), yields $\mu \approx 2 \times 10^{15} \mathrm{~Pa}$. Then, solving Equation (11) for $u$ gives $u<\approx 12 \mathrm{~m} \mathrm{a}^{-1}$, which falls within the error limits of the observations.

In the vicinity of ice raft " $a$ ", the driving stress for ice flow varies from 20 to $2 \mathrm{kPa}$ or less (Bindschadler and others, 1987). A sticky spot spanning kilometers with a shear stress a few $\mathrm{kPa}$ higher than its surroundings may be a significant feature in the force balance there, even though there is no large velocity difference between it and its surroundings. A strain grid across its margins or very accurate velocity measurements would be needed to learn whether ice raft " $a$ " is moving slower than its surroundings and acting as a sticky spot.

A careful calculation would allow for the elliptical shape of the ice raft and for some other factors, but it does not seem warranted given the lack of a strain grid or detailed measurements of surface topography across the ice raft. In general, for a sticky spot of given area, an elliptical form elongated parallel to ice flow would give a larger velocity differential for a given drag than for a circular feature, making it easier to detect an elliptical sticky spot through measurement of differential velocity.

\subsection{Bedrock roughness: the form drag of knobs}

The seismic surveys of Ice Stream B by Rooney and

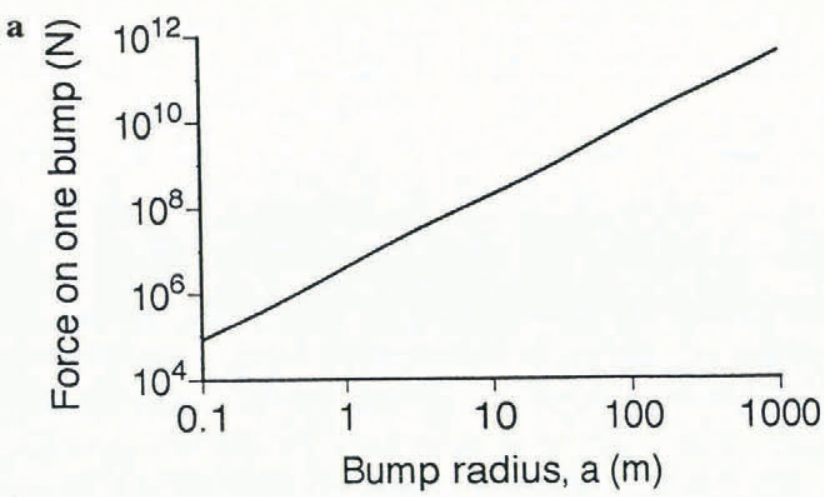

b

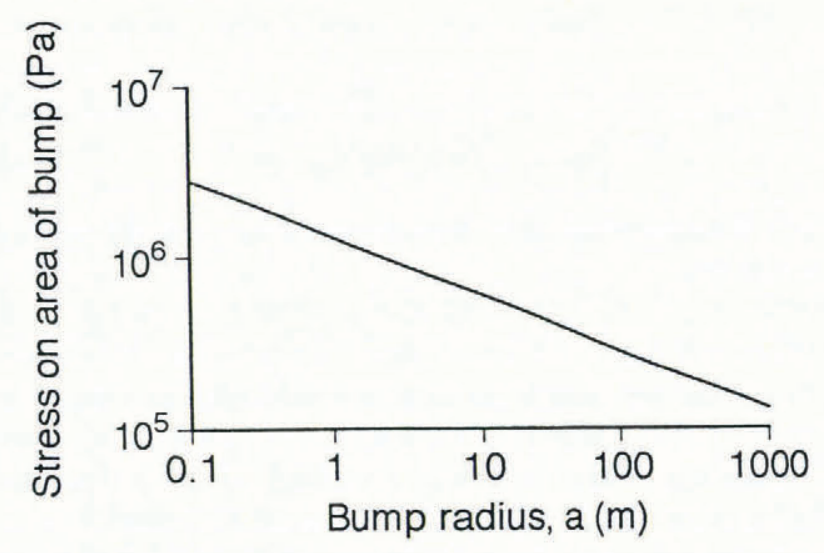

c

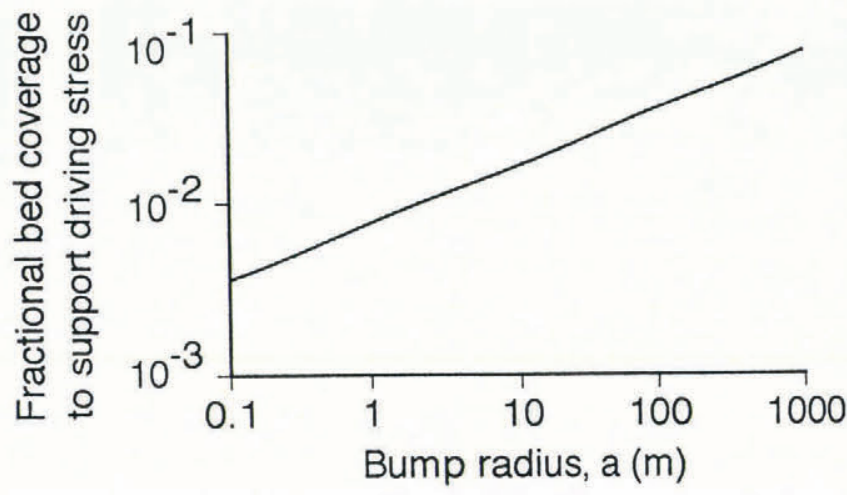

Fig. 2. Form drag of large, hemispherical bedrock bumps for Ice Stream B, as a function of bump radius $a$. The drag, $D$, on a bump, from the power-law generalization of the solution of Watts (1974; quoted in Hallet, 1979), is taken to be $D=0.5 \pi\left(\omega a^{5} u / A\right)^{\frac{1}{3}}$, with $\omega$ taken as the average of the values 4 and 6 for free-slip and no-slip boundaries, respectively, and $A=5 \times 10^{-24} \mathrm{~Pa}^{-3} \mathrm{~s}^{-1}$ for temperate ice (Paterson, 1981, p.39). a. Force on a single bump. $b$. Stress from form drag of a bump on its basal area $\pi a^{2}$. c. Fraction of bed that must be covered by bumps of one size to support the entire driving stress for ice flow at the ice-stream velocity.

others (1987) showed that roughness elements $>O(1 \mathrm{~m})$ are largely or completely absent. However, analyses of images of Ice Stream D by Bindschadler and Scambos (1991) indicate that bedrock roughness at the length scale of $O(h)$ may be important there.

For an ice velocity of $450 \mathrm{~m} \mathrm{a}^{-1}$, appropriate for Ice Stream B or the other Siple Coast ice streams, Equation (7) shows that the drag force from bedrock bumps can be 
large. Results of calculations are shown in Figure 2. Covering $<1 \%$ of the glacier bed with $1 \mathrm{~m}$ radius, fixed hemispherical bumps, or $<2 \%$ of the bed with $10 \mathrm{~m}$ radius bumps, would support the entire basal shear stress if it were $10 \mathrm{kPa}$.

Features $>O(1-10 \mathrm{~m})$ might be detected by direct imaging using closely spaced radar or seismic lines. Smaller-scale features $(O(0.1-1 \mathrm{~m}))$ could be detected by statistical analysis of fading patterns from radar experiments (e.g. Walford and others, 1986; Bentley and Novick, 1990). The theory of form drag by bumps is relatively well developed (e.g. Weertman, 1964; Lliboutry, 1987), so good data on local bed configuration could be used to calculate stickiness. Such experiments, if located in regions where imagery shows disturbance of the surface, probably offer the best change of identifying sticky spots.

\section{CONCLUSIONS}

Field data suggest that the basal drag on Siple Coast ice streams is spatially variable, and that localized "sticky spots" may exist within well-lubricated regions. Sticky spots might range from $O(1-10 \mathrm{~m})$ to $O(10 h)$, where $h$ is the ice thickness. Smaller features are included in local sliding laws and larger features are detected by modern geophysical surveys and are resolved by modern ice-flow models.

Sticky spots might be caused by (near-)discontinuity of a deformable subglacial till if such a till limits the basalshear stress beneath much of an ice stream. However, lubrication by till requires high basal-water pressures, which also would occur over a sticky spot surrounded by till and which are known to promote basal sliding as well as bed deformation. Mountain glaciers with shear stresses approaching $100 \mathrm{kPa}$ and with basal-water pressures typical of Ice Stream B exhibit sliding velocities similar to the velocity of Ice Stream B, suggesting that mere discontinuity of till cannot lead to exceptionally high shear stresses on sticky spots.

Weertman (1972) and Robin and Weertman (1973) suggested that subglacial water pressure in a distributed system decreases with increasing shear stress, and that sliding velocity increases with water supply and shear stress. If a sticky spot were sufficiently sticky, then water would flow into it from all sides until it became sufficiently lubricated to lower its shear stress enough to allow steady water drainage. For likely values of constants, this places a more restrictive limit on the shear stress on a sticky spot beneath Ice Stream B. If there is no topographic expression of the sticky spot, then the shear stress on it can be only a few tens of $\mathrm{kPa}$ above the lubricated, regional value. A basal high will increase the stickiness a little and a surface high is about ten times more effective than a basal high at increasing shear stress. Ice raft " $a$ " in Ice Stream B may be such a surface-high sticky spot; a strain grid across the margin of this feature would clarify this point.

If the Weertman (1972) postulate is correct and sticky spots have a lower water pressure than adjacent, welllubricated areas, then water-pressure measurements might detect or confirm the existence of sticky spots.
However, the water-pressure drop over sticky spots is calculated to be similar to the measurement error using modern techniques and so may not be detectable.

Regardless of its effect on water flow, a bedrock knob restrains ice flow through its form drag, which is large at ice-stream velocities. This effect is nearly independent of lubrication tangential to the knob surface - a bedrock knob that sticks into an ice stream lubricated over most of its bed by deforming till restrains the ice whether the deforming till goes over or around the knob. Such knobs can be identified by direct imaging (radar or seismic) or by their effects on radar or seismic fading patterns and their effects can be calculated.

For the region of Ice Stream B studied by Rooney and others (1987) and Rooney (1988), it is unlikely that sticky spots support a large fraction of the driving stress for ice flow. If the basal shear stress is a significant fraction of the driving stress, then the strength or viscosity of the subglacial sediments, which cover a large fraciton of the bed, must be important.

\section{ACKNOWLEDGEMENTS}

I thank K. M. Cuffey, C. F. Raymond, R. C. A. Hindmarsh, S. Anandakrishnan and the Chief Editor of the Journal for helpful suggestions. This research was supported in part by funds from the U.S. National Science Foundation Division of Polar Programs, and by funds from the David and Lucile Packard Foundation.

\section{REFERENCES}

Alley, R. B. 1989a. Water-pressure coupling of sliding and bed deformation: I. Water system. J. Glaciol., 35(119), 108-118.

Alley, R.B. 1989b. Water-pressure coupling of sliding and bed deformation: II. Velocity-depth profiles. f. Glaciol., 35(119), 119 129

Alley, R. B., D. D. Blankenship, C. R. Bentley and S. T. Rooney. 1987a. Continuous till deformation beneath ice sheets. International Association of Hydrological Sciences (Symposium at Vancouver 1987 - The Physical Basis of Ice Sheet Modelling), 81-91.

Alley, R. B., D. D. Blankenship, C. R. Bentley and S. T. Rooney. 1987b. Till beneath Ice Stream B. 3. Till deformation: evidence and implications. 7. Geophys. Res., 92(B9), 8921-8929.

Anandakrishnan, S. and C. R. Bentley. 1993. Microearthquakes beneath Ice Streams B and C, West Antarctica: observations and implications. 7. Glaciol., 39(133), 455-462.

Atre, S. R. and C. R. Bentley. 1990. Laterally varying basal conditions under Ice Stream C, Antarctica. [Abstract.] Eos, 71(43), 1303.

Balise, M.J. and C.F. Raymond. 1985. Transfer of basal sliding variations to the surface of a linearly viscous glacier. F. Glaciol., 31(109), 308-318.

Batchelor, G.K. 1967. An introduction to fluid dynamics. Cambridge, Cambridge University Press.

Bentley, C. R. and A. N. Novick. 1990. Relative motion between the top and bottom surfaces of Ice Stream B, Antarctica. [Abstract.] Eos, $71(43), 1307$.

Bindschadler, R. A. and T.A. Scambos. 1991. Satellite-image-derived velocity field of an Antarctic ice stream. Science, 252(5003), 242-246.

Bindschadler, R. A., S. N. Stephenson, D. R. MacAyeal and S. Shabtaie. 1987. Ice dynamics at the mouth of Ice Stream B, Antarctica. J Geophys. Res., 92(B9), 8885-8894.

Blankenship, D. D., S. Anandakrishnan, J. L. Kempf and C. R. Bentley. 1987a. Microearthquakes under and alongside Ice Stream B, Antarctica, detected by a new passive seismic array. Ann. Glaciol., 9, 30-34.

Blankenship, D. D., C. R. Bentley, S. T. Rooney and R. B. Alley. 1987 b. 
Till beneath Ice Stream B. 1. Properties derived from seismic travel times. F. Geophys. Res., 92(B9), 8903-8911.

Engelhardt, H., N. Humphrey, B. Kamb and M. Fahnestock. 1990. Physical conditions at the base of a fast moving Antarctic ice stream. Science, 248(4951), 57-59.

Hallet, B. 1979. A theoretical model of glacial abrasion. J. Glaciol., 23(89), 39-50.

Hughes, T. 1977. West Antarctic ice streams. Rev. Geophys. Space Phys., 15(1), $1-46$.

Iken, A. and R. A. Bindschadler. 1986. Combined measurements of subglacial water pressure and surface velocity of Findelengletscher, Switzerland: conclusions about drainage system and sliding mechanism. J. Glaciol., 32(110), 101-119.

Kamb, B. 1970. Sliding motion of glaciers: theory and observation. Rev. Geophys. Space Phys., 8(4), 673-728.

Kamb, B. 1987. Glacier surge mechanism based on linked cavity configuration of the basal water conduit system. F. Geophys. Res., 92(B9), 9083-9100.

Kamb, B. 1991. Rheological nonlinearity and flow instability in the deforming bed mechanism of ice-stream motion. J. Geophys. Res., 96(B10), 16,585-16,595.

Kamb, B. and 7 others. 1985. Glacier surge mechanism: 1982-1983 surge of Variegated Glacier, Alaska. Science, 227 (4686), 469-479.

Lliboutry, L. 1987. Realistic, yet simple bottom boundary conditions for glaciers and ice sheets. 7. Geophys. Res., 92(B9), 9101-9109.

MacAyeal, D. R. 1992. The basal stress distribution of Ice Stream E, Antarctica, inferred by control methods. 7. Geophys. Res., 97(B1), 595-603.

Nye, J.F. 1969. A calculation on the sliding of ice over a wavy surface using a Newtonian viscous approximation. Proc. R. Soc. London, Ser. A, 311, 445-467.

Paterson, W. S. B. 1981. The physics of glaciers. Second edition. Oxford, etc., Pergamon.

Robin, G.de Q. and J. Weertman. 1973. Cyclic surging of glaciers. F. Glaciol., 12(64), 3-18.

Rooney, S. T. 1988. Subglacial geology of Ice Stream B. (Ph.D. thesis, University of Wisconsin-Madison.)
Rooney, S. T. 1988. Subglacial geology of Ice Stream B. (Ph.D. thesis, University of Wisconsin-Madison.)

Rooney, S. T., D. D. Blankenship, R. B. Alley and C. R. Bentley. 1987. Till beneath Ice Stream B. 2. Structure and continuity. F. Geophys. Res., 92(B9), 8913-8920.

Shabtaie, S. and C.R. Bentley. 1987. West Antarctic ice streams draining into the Ross Ice Shelf: configuration and mass balance. $\mathcal{f}$. Geophys. Res., 92(B2), 1311-1336.

Shabtaie, S. and C.R. Bentley. 1988. Ice-thickness map of the West Antarctic ice streams by radar sounding. Ann. Glaciol., 11, 126-136.

Vornberger, P.L. and I.M. Whillans. 1986. Surface features of Ice Stream B, Marie Byrd Land, West Antarctica. Ann. Glaciol., 8, 168170 .

Walder, J. S. 1986. Hydraulics of subglacial cavities. F. Glaciol., 32(112), 439-445.

Walford, M. E. R., M. I. Kennett and P. Holmlund. 1986. Interpretation of radio echoes from Storglaciären, northern Sweden. $\mathcal{F}$. Glaciol., 32(110), 39-49.

Watts, P. A. 1974. Inclusions in ice. (Ph.D. thesis, University of Bristol.)

Weertman, J. 1964. The theory of glacier sliding. F. Glaciol., 5(39), 287303.

Weertman, J. 1972. General theory of water flow at the base of a glacier or ice sheet. Rev. Geophys. Space Phys., 10(1), 287-333.

Weertman, J. 1986. Basal water and high-pressure basal ice. F. Glaciol., 32(112), 455-463.

Whillans, I. M. and S.J. Johnsen. 1983. Longitudinal variations in glacial flow: theory and test using data from the Byrd Station strain network, Antarctica. F. Glaciol., 29(101), 78-97.

Whillans, I. M. and C.J. van der Veen. 1993. Patterns of calculated basal drag on Ice Streams B and C, Antarctica. F. Glaciol., 39(133), 437-446.

Whillans, I. M., J. Bolzan and S. Shabtaie. 1987. Velocity of Ice Streams B and C, Antarctica. F. Geophys. Res., 92(B9), 8895-8902.

The accuracy of references in the text and in this list is the responsibility of the author, to whom queries should be addressed. 